\title{
Toward Unraveling the Photochemistry of TATB
}

M.R. Manaa, R. Schmidt, G. Overturf, B. Watkins, L. Fried, J. Kolb

\section{November 2, 1999}

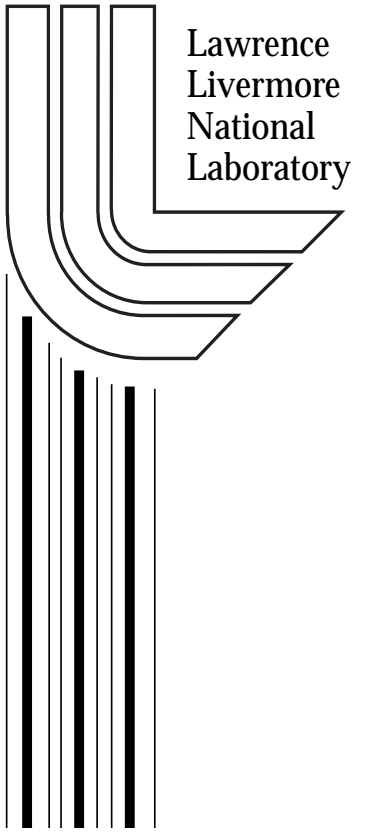




\section{DISCLAIMER}

This document was prepared as an account of work sponsored by an agency of the United States Government. Neither the United States Government nor the University of California nor any of their employees, makes any warranty, express or implied, or assumes any legal liability or responsibility for the accuracy, completeness, or usefulness of any information, apparatus, product, or process disclosed, or represents that its use would not infringe privately owned rights. Reference herein to any specific commercial product, process, or service by trade name, trademark, manufacturer, or otherwise, does not necessarily constitute or imply its endorsement, recommendation, or favoring by the United States Government or the University of California. The views and opinions of authors expressed herein do not necessarily state or reflect those of the United States Government or the University of California, and shall not be used for advertising or product endorsement purposes.

Work performed under the auspices of the U. S. Department of Energy by the University of California Lawrence Livermore National Laboratory under Contract W-7405-Eng-48.

This report has been reproduced directly from the best available copy.

Available to DOE and DOE contractors from the

Office of Scientific and Technical Information

P.O. Box 62, Oak Ridge, TN 37831

Prices available from (423) 576-8401

http://apollo.osti.gov/bridge/

Available to the public from the National Technical Information Service

U.S. Department of Commerce 5285 Port Royal Rd., Springfield, VA 22161 http://www.ntis.gov/

OR Lawrence Livermore National Laboratory Technical Information Department's Digital Library http://www.llnl.gov/tid/Library.html 


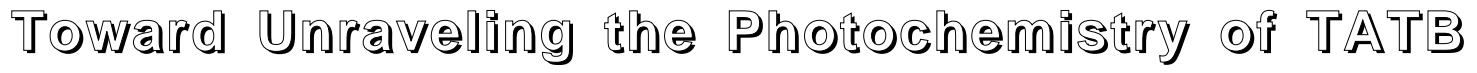

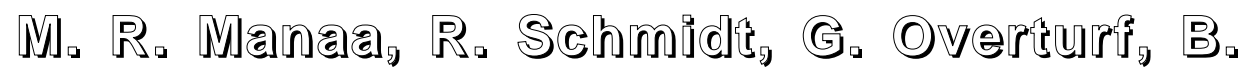 Waiksins, L. F[ied, and J. Kolb
}

\author{
Lawrence Livermore National Laboratory \\ Livermore, California 94551
}

\begin{abstract}
A combined theoretical and experimental chemical analysis has been conducted to unravel the mechanism underlying the color change of yellow TATB $(1,3,5$, triaminotrinitro-benzene) to green upon UV irradiation. There is strong evidence to conclude that the process is photochemical in nature and due to the formation of the mono nitroso derivative. We have identified a chemical synthesis by which this derivative compound can be produced in the laboratory, thus allowing for direct testing and determination of its chemical and physical properties. Calculations also show only a slight decrease in the sensitivity and performance of the irradiated materials, attributed to the formation of this previously unidentified species.
\end{abstract}

\section{INTRODUCTION}

A peculiar property of the insensitive explosive TATB $(1,3,5-$ triamino-2,4,6-trinitrobenzene, Figure 1 ) is a change in color from yellow of the freshly prepared sample, to green

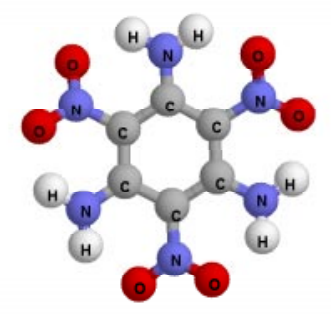

Figure 1. Molecular TATB. upon exposure to a radiation stimulus (Figure 2). This darkening is a surface phenomenon, increases with penetrating radiation. If this effect is due to chemical decomposition, it certainly raises some concern and issues to consider regarding the bulk properties such as performance and sensitivity. Differential Scanning Calorimetry (DSC) results, for example, showed ${ }^{1}$ a 10-degree decrease in the onset of reaction exotherm of the light induced green material, and a 15-degree reduction ${ }^{2}$ for gamma induced dark green 
materials. As this explosive might be exposed to a penetrating radiation in the stockpile environment, the formation of green materials is an aging signature that is readily manifested, with consequences to the service lifetime. Identification of the mechanism and the species, if any, causing this aging trend is the object of this work.

There have been numerous, albeit inconclusive studies regarding the "greening" of TATB. In the early 80 's, Britt et al. ${ }^{3}$ measured the ESR spectra of UV photolyzed TATB both in the solid phase and in solution. They proposed that the coloring is due to the formation of unusually stable radical, with no evidence of decaying after two years, of H-adduct TATB (I).<smiles>[2H]N(O)c1c(N)c([N+](=O)[O-])c(N)c(N)c1[N+](=O)[O-]</smiles>

I

Their results were later contradicted ${ }^{4}$ based on semi empirical molecular orbital calculations of spin density.

More recently, a group at LANL found ${ }^{2}$ evidence for the formation of mono (II) and di (III) furazans in gamma and proton irradiated samples of doses 17 and 70 megarads. These substances were not detected in a sample with 9 Mrad radiation, although lime green in color.<smiles></smiles><smiles>Nc1c([N+](=O)[O-])c2nonc2c2nonc12</smiles>

III

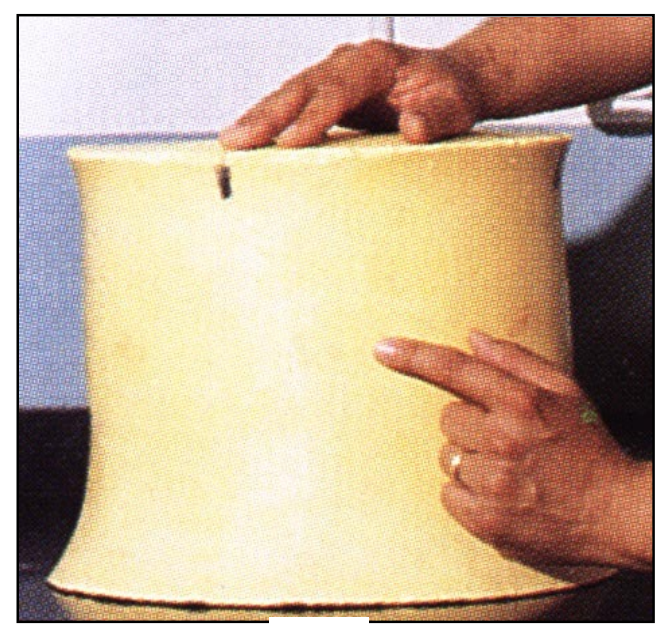

a

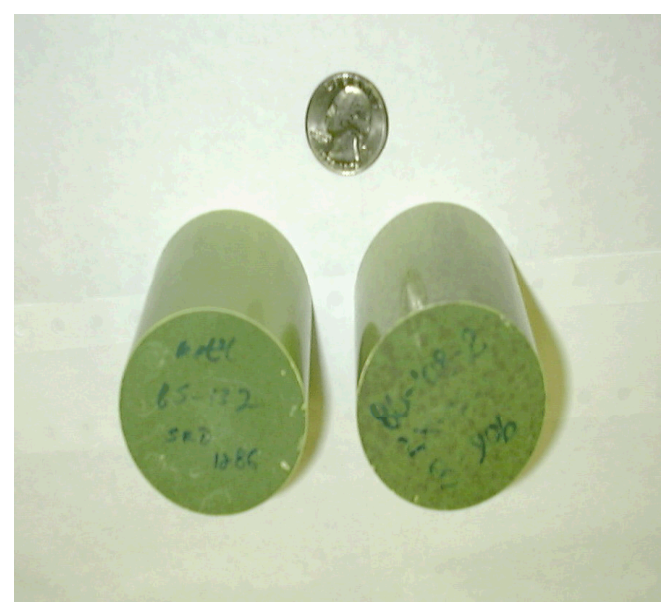

b

Figure 2. TATB samples of a) freshly prepared, and b) after irradiation. 
The above noted studies have thus determined that the greening effect is chemical in nature, due to the production of new species. Since this effect is a surface phenomenon, reliable identification of the new species is hindered by its low concentration in the bulk materials, and by the low solubility of both the original and contaminant materials. It is highly desirable and more advantageous to reproduce the new species directly by synthetic methods. We should note that decomposition products of TATB due to a variety of external stimuli (shock, impact, and heat) have also been identified.

The present work combines theoretical modeling and experimental chemical analysis of control (untreated), irradiated (70 Mrad irradiated sample of LANL, and a UV irradiated sample created in $12 / 93$ by F. Foltz at LLNL), and green synthesized (of R. Schmidt et.al., LLNL, see below) TATB samples. Spectroscopic determinations included infrared (IR), $\mathrm{UV}$, and mass spectra (high resolution and positive electron impact, PEI).

\section{RESULTS \& DISCUSSION}

The visible region of the electromagnetic spectrum extends in the approximate range of $400-800 \mathrm{~nm}$, the green color occurring at $\sim 550 \mathrm{~nm}$. The absorption of light can be modeled as electrons are excited to higher energy levels. We have calculated, using semiempirical methods, the UV spectra of TATB and all previously proposed decomposition products (I-III). We note that due to increase bond conjugation the mono and di furazans should be primary suspects for coloration.
We have also calculated the UV spectra of the mono nitroso analog of TATB (Figure 3, referred to as TADNB). Nitroso derivatives are known to be colored. Consider the simple case of nitrobenzene and nitrosobenzene. While both spectra show strong absorption in 250-300 nm region, the nitrosobenzene spectrum shows and additional weak absorption at $750 \mathrm{~nm}$. Further, mono nitroso analogs have been determined to be major products in thermal decomposition experiments. ${ }^{7,8}$ Interestingly, the calculated UV spectrum of TADNB (figure 4) shows a weak absorption at 600 nm.

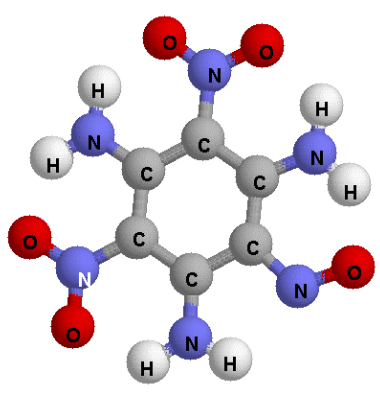

Figure 3. Mono nitroso anolog of TATB (TADNB)

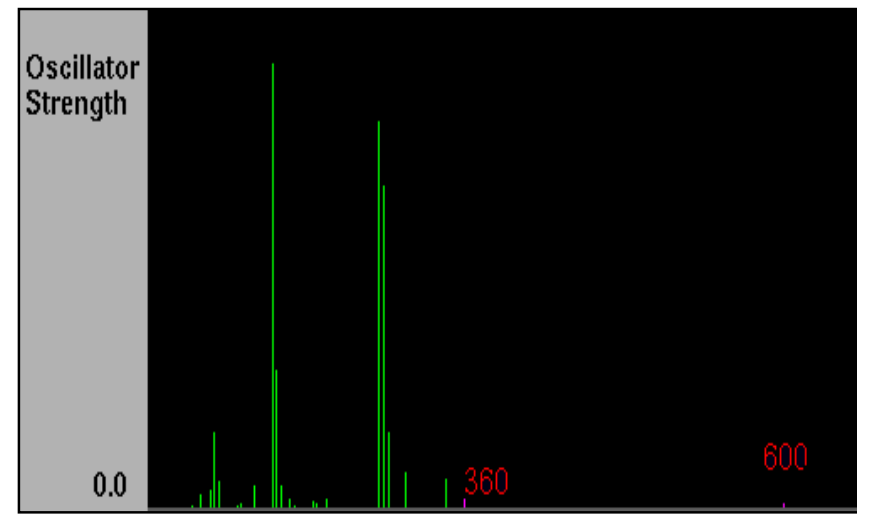

Figure 4. Calculated UV spectrum of TADNB 
TADNB seems to be the major contaminant in a new, direct synthesis of TATB $^{9}$, using the following scheme:

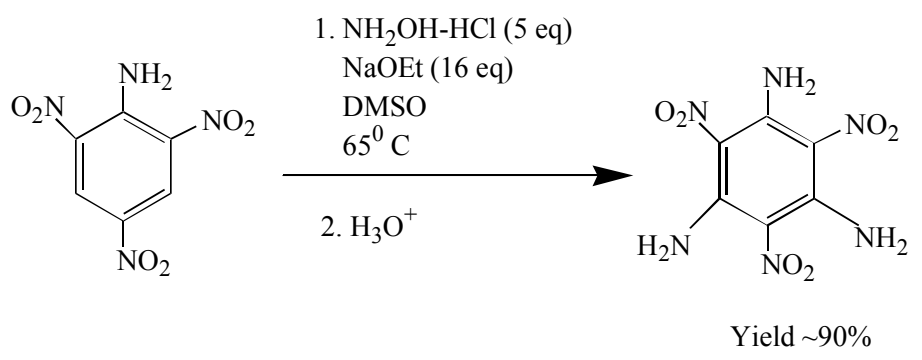

The mass spectrum of untreated, yellow TATB (figure 5) shows peaks at 258 and 228 due to TATB and the loss of NO. The spectra of both light irradiated and the synthesized materials (as described in the above scheme) exhibit additional peaks at 242 and 225 (figure 6). The peak at 242 corresponds to the molecular weight of TADNB, and is of the same intensity for aged and synthesized species. Highresolution mass spectroscopy recorded similar results. That the peak of at 242 a.m.u. is due to the loss of an oxygen atom and not, say, an amine group $\left(\mathrm{NH}_{2}\right)$ is accounted for on the basis of the definitive results obtained from the high resolution mass spectra, and taking into account that DATB produces a different mass spectra. Note that, based on our ab initio quantum mechanical calculations, breaking the $\mathrm{C}-\mathrm{NH}_{2}$ bond requires $104 \mathrm{kcal} / \mathrm{mol}$, significantly more than that required for the rupture of the N-O bond, $76 \mathrm{kcal} / \mathrm{mol}$. An UV spectrum recorded on the synthesized materials showed a very weak absorption at $600 \mathrm{~nm}$. This is not definitive, however, due to relatively small concentration of the materials in the sample (which also seems to have the same solubility characteristics of TATB). Further analysis of the synthesized TADNB (purification, isolation, and $\mathrm{X}$ ray characterization) is still needed. Finally, we note that this species has been detected as a major product in early shock-induced decomposition of TATB. ${ }^{10}$

The production of a di nitroso compound and the loss of $\mathrm{OH}$ can account for the presence of the peak at 225 radical from TADNB as in the following scheme:

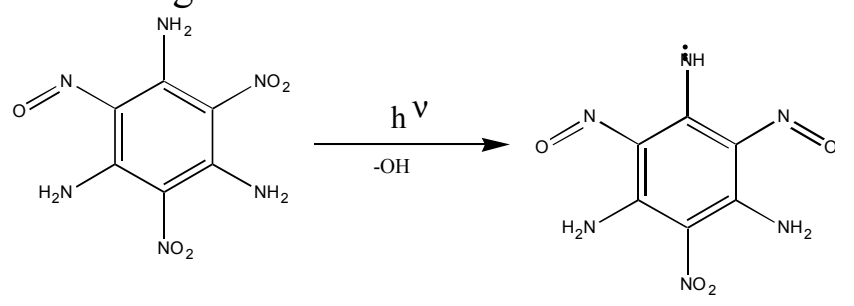

A mass spectrum of TADNB (MSMS) shown in figure 7, clearly identifies TADNB as the source for the production of the 225 compound.

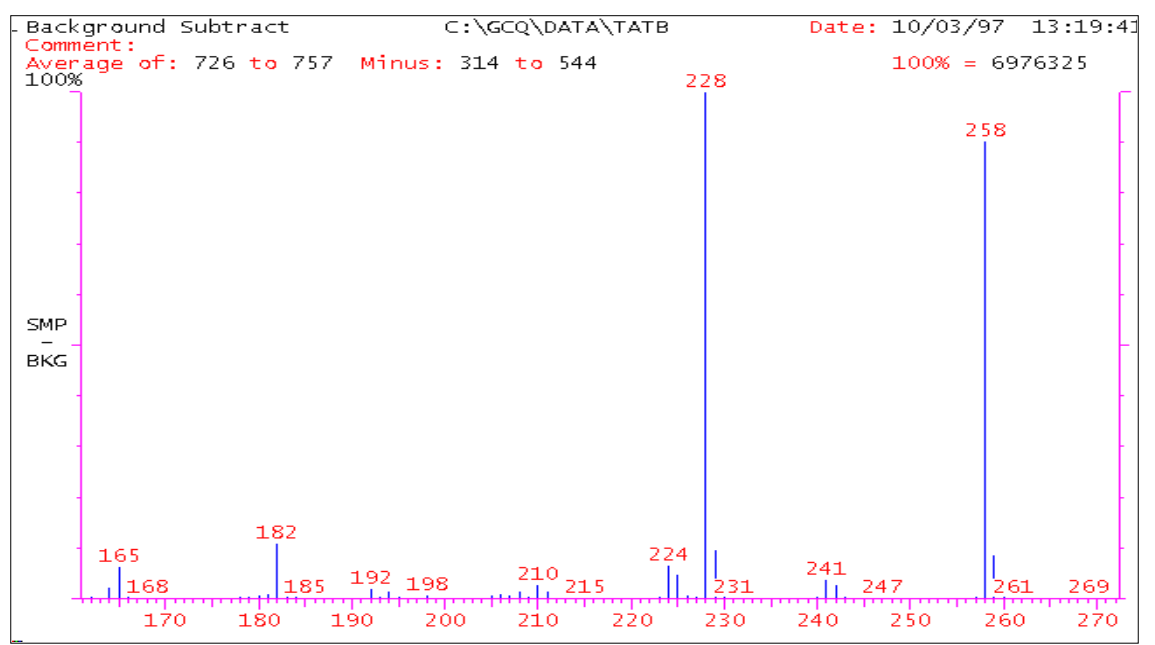

Figure 5. PEI mass spectrum of untreated TATB 


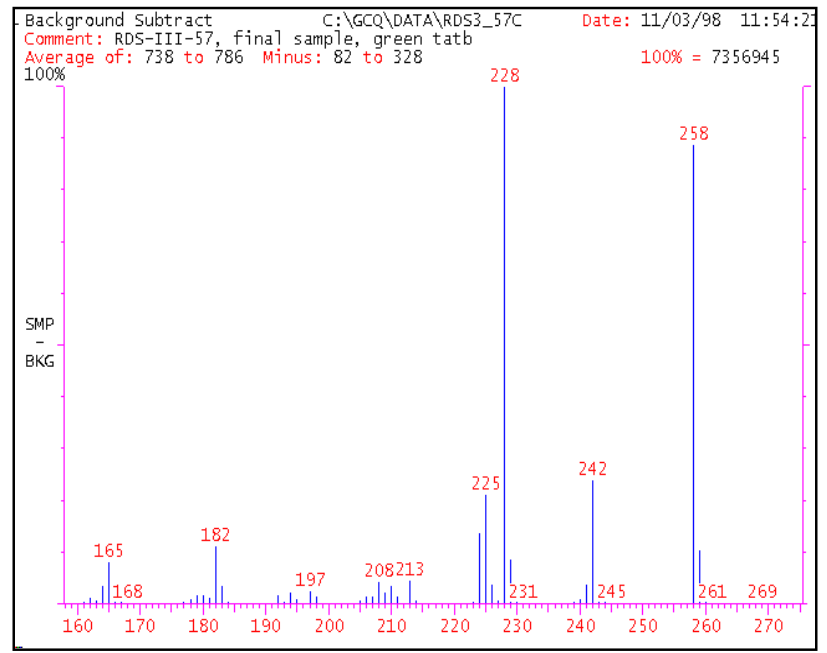

Figure 6. The mass spectrum of synthesized DATNB. Similar spectrum is obtained from the aged, light irradiated TATB.

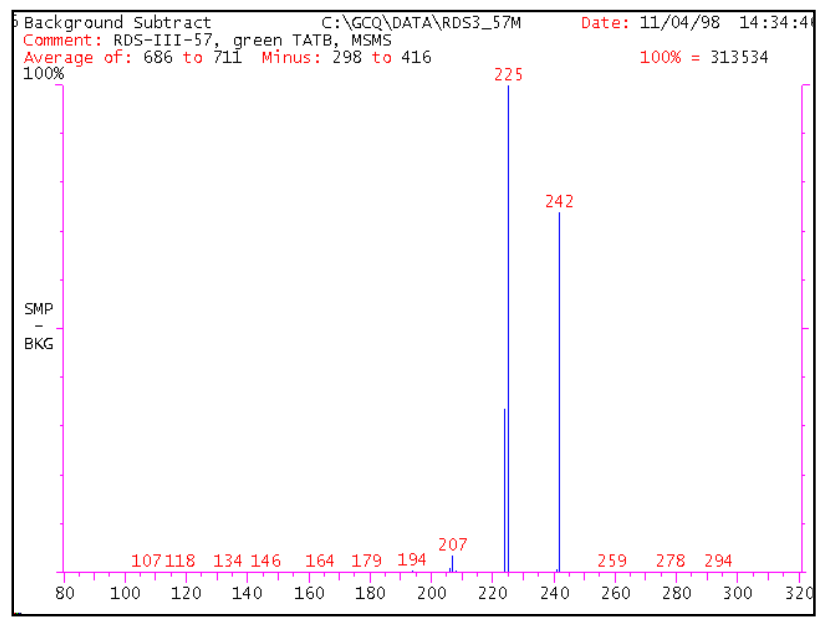

Figure 7. MSMS, mass spectrum indicating the production of the 225 fragment from TADNB.

The calculated IR spectrum of TADNB is shown in figure 8 . We note the strong absorption at 1361 and 1625 $\mathrm{cm}^{-1}$. The strongest of the double peaks around $1625 \mathrm{~cm}^{-1}$ is due to the $\mathrm{NO}_{2}$ asymmetric stretch and the weaker peak is due to the $\mathrm{N}=\mathrm{O}$ stretch. Only one peak should be observed in nonirradiated TATB samples. It is doubtful, however, that these peaks can be resolved experimentally.

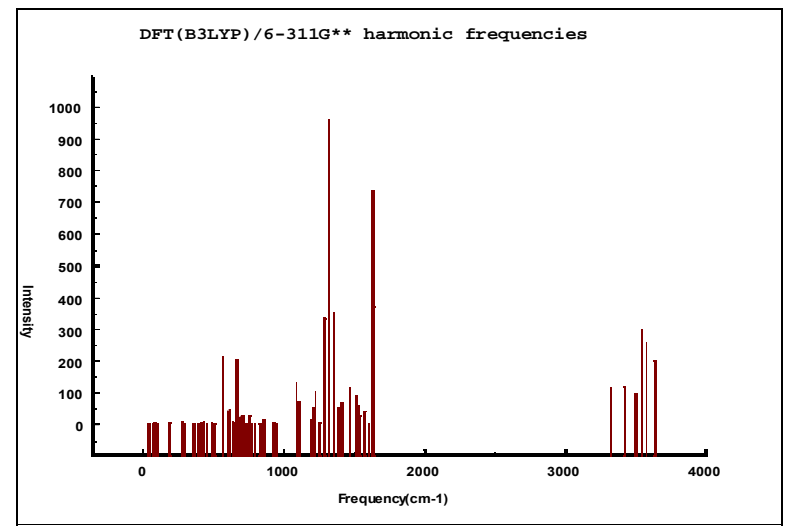

Figure 8. Calculated harmonic frequencies of TADNB.

Figure 9 shows a recorded IR spectra of the four samples. It allows for a quick comparison of the different samples which are remarkably similar in all respects except for the synthetic byproduct whose symmetric angle deformation of the $\mathrm{NH}_{2}$ group $\left(1638.2 \mathrm{~cm}^{-1}\right)$ appears $5 \mathrm{~cm}^{-1}$ lower than the rest. To see the doublet around $1625 \mathrm{~cm}^{-1}$ may require Raman spectroscopy.

As for the aduct-H species, I, quantum chemical calculations confirmed that it is unstable, having no equilibrium potential energy minimum. The formation of this species is, thus, precluded since no evidence of its existence appears in the mass spectra. 


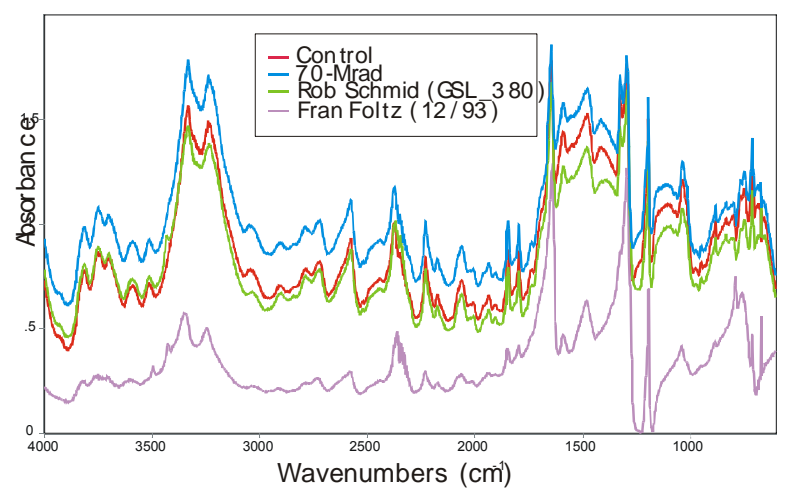

Figure 9. Diffuse reflectance IR of control and green TATB samples obtained using SpectraTech DRIFT accessory in a Nicolet 730. 256 scans at $1 \mathrm{~cm}^{-1}$ resolution.

Finally, an estimate for the change to detonation sensitivity and performance, due to the formation of TADNB, has been determined using calculated heat of formation characteristics of this species and the thermochemical code CHEETAH.

Performance calculations were based on assuming that the density of TADNB is the same as that of TATB. The heat of formation of TADNB was calculated to be $-19 \mathrm{kcal} / \mathrm{mol}$. This compares with a heat of formation of $-35 \mathrm{kcal} / \mathrm{mol}$ for TATB. In order to assess the difference in performance of the materials, we calculated the energy released at a relative volume expansion of 2.2. This is a common metric in determining the metal acceleration ability of an explosive. The calculated performance of TADNB at its crystal density was $6 \%$ less than that of TATB at the same density. This is due to the poorer oxygen balance of TADNB.

Safety calculations were based on calculating the strength of the weakest bond in the molecule. We have been able to show that this often correlates with explosive sensitivity. The calculated bond dissociation energy of $64 \mathrm{kcal} / \mathrm{mol}$ leads to a predicted drop hammer height of $100 \mathrm{~cm}$. Thus, TADNB is predicted to be an insensitive high explosive, but more sensitive than TATB $(>300 \mathrm{~cm}$ hammer height). Small quantities of TADNB are thus not expected to significantly sensitize TATB.

\section{SUMMARY:}

Our work indicates that there is considerable evidence that the production of green TATB is a photochemical process accompanied with the formation of mono nitroso analog (TADNB). A synthetic route for the production of this species under controlled laboratory conditions has been identified. Additional work requires the isolation and purification of this material in appropriate quantities for conclusive identification and further testing.

\section{REFERENCES:}

1 M. F. Foltz, D. L. Ornellas, P. F. Pagoria, and A. R. Mitchell, Journal of Material Science 31, 1893-1901 (1996).

2 C. B. Skidmore, D. J. Idar, G. A. Buntain, S. F. Son, and R. K. Sander, in Life Cycles of Energetic Materials (Fulerton, California, 1998).

3 A. D. Britt, W. B. Moniz, G. C. Chingas, D. W. Moore, C. A. Heller, and C. L. Ko, Propellants and Explosives 6, 94-95 (1981).

4 D. W. Firsich and M. P. Guse, Journal of Energetic Materials 2, 205-214 (1984).

5 J. Sharma and F. J. Owens, Chemical Physics Letters 61, 280-282 (1979).

6 J. Sharma, J. W. Forbes, C. S. Coffey, and T. P. Liddiard, Journal of Physical Chemistry 91, 5139-5144 (1987). 
7 R. Behrens and S. Bulusu, J. Phys. Chem. 96, 8877-8891 (1992).

8 R. Behrens and S. Bulusu, in Chalanges in Propellants \& Combustions 100 Years after Nobel, edited by K. Kuo (Begell House, Inc., 1997), pp. 275-289.

9 R. D. Schmidt, A. R. Mitchell, G. S. Lee, P. P. Pagoria, M. D. Coburn, M. Cates, W. T. Quinlan, and R. Thorpe, (Lawrence Livermore National Laboratory, Livermore, 1998).

10 H. stmark, in the proceedings of Shock Compression of Condensed Matter, edited by S.C. Shmidt and W.C. Tao (AIP Press, 1996), pp. 871-874. 